\title{
EFFECT OF CHOPPING OIL PALM FRUIT SPIKELETS ON THE FREE FATTY ACID CONTENT RELEASE RATE AND ITS MECHANICAL PROPERTIES
}

\author{
Fatin S.A. ${ }^{1}$, Rosnah $S^{2}$,Yunus, $\mathbf{R}^{3}$ \\ ${ }^{1,2}$ Department of Process and Food Engineering, Faculty of Engineering, Universiti Putra Malaysia, 43400 Serdang, \\ Selangor \\ ${ }^{3}$ Institute of Advanced Technology, Universiti Putra Malaysia, 43400 Serdang, Selangor
}

\begin{abstract}
Crushed oil palm fruit bunches from the continuous sterilization system cause damages and bruising of the fruits, yielding high lipase enzyme reaction if no heating pre-treatment was carried out immediately. Thus, this study was proposed to acquire the free fatty acid content (FFA) release rate and to determine the mechanical properties of chopped oil palm fruit spikelets. The fruit spikelets were chopped by using two different methods, which were manually chopping using a knife blade and utilizing a fabricated chopper blade. Damages obtained from the manually chopped using the knife blade were classified into two categories, which were minor and major damage. The chopper blade was fixed on the Instron Machine to obtain its mechanical properties, such as rupture force, deformation at rupture, hardness and energy at the break of the fruit spikelets. The chopped fruit spikelets were stored at different storage periods ranging between $\mathrm{Ohr}$ to $2 \mathrm{hr}$ at room temperature. Extraction of palm oil was extracted using the Soxhlet extractor and the FFA content of the palm oil was determined through titration method. Results showed that the mean rupture force, deformation at rupture, hardness and energy at break required when chopping the fruit spikelets were 2781N, $45.53 \mathrm{~mm}, 61.02 \mathrm{~N} / \mathrm{mm}$ and $36.71 \mathrm{~J}$ respectively. The development of FFA content was highly influenced by the damaged area of the fruits and the length of storage periods. This is due to the development of lipase enzyme activity that occurred in the damaged cells, therefore simultaneously increasing the rate of FFA content released.
\end{abstract}

Key Words: Oil Palm Fruit Spikelets, Chopping Methods, Mechanical Properties, Storage Periods, Free Fatty Acid Content.

\section{INTRODUCTION}

The oil palm or (Elaeis guineensis Jacq) is a very famous plant and it is known as the tree of life since it has many benefits. It is believed that the origin of the oil palm is from the West and Central of Africa. Oil palm fruit is an ovalshaped drupe and it is clustered in a large bunch of fruit. The weight of the fruit bunch ranges between $10 \mathrm{~kg}$ to $40 \mathrm{~kg}$ depends on the size and age, and the fruitlet ranges from 6 to 20 grammes [1].

The ripe fresh fruit bunches (FFB) are harvested and sent to the mill to extract the crude palm oil within 24 hours. In Malaysia, most of the mills use conventional sterilizer instead of continuous, vertical and other sterilizers. Sterilization process is the critical process in order to inactivate the lipolytic enzyme, prevent the development of free fatty acids (FFA) and ease the fruits stripping process [2]. During this process, the whole fruit bunches are loaded into cages and undergoes high pressurized steaming at 40 psi for about 70 to $90 \mathrm{~min}$ to ensure the heat is capable of facilitating the detachment of fruitlets [3]. The various sizes of FFB, the close-knit arrangement of spikelets and the depth of the inner layers cause the heat difficult to penetrate.
This result in an ineffective sterilization process which produces a high percentage of unstripped bunches (USB).

Conversely, the continuous sterilization crushes the closeknit arrangement of the fruit bunches into smaller size using a double - roll crusher. Then, the fruit bunches are sprayed with live steam at atmospheric pressure before being conveyed to the next process. At current, the continuous sterilization systems are successfully implemented by sixteen mills in Malaysia while three mills are still under construction [4]. The results proved that the continuous sterilization process improves the strippability of bunches, lowers the operating and maintenance costs, and provides a cleaner and safer environment. In addition, the oil extraction rate (OER) appears to be maintained as well as above $21 \%$ [4].

However, the continuous sterilization causes a lot of oil loss in condensate and oil palm stalks. The oil quality such as the free fatty acid (FFA) content is also affected if no heating steps are taken after crushing the fruit bunches [3]. For example, if the conveyor chain has broken, the process must be stopped for repair and maintenance. At times like this, extensive time is needed for the crushed fruit bunches to be taken out and transferred to the other sterilizer. This leads to 
the crushed fruit bunches with many bruises to be highly affected to the microorganisms. Simultaneously, the increment of the free fatty acid (FFA) content will occur. FFA is the most important quality that reflects the quality of crude palm oil (CPO). According to the global standard of oil quality specification, the FFA content of CPO must be less than 5\% [5]. The lower FFA content indicates a better quality of the CPO.

Many studies were done to investigate the factors that influenced the FFA content. A study was done by Hadi et al 2009 to determine the correlation between the different categories of oil palm fruitlets bruising to the FFA content. It was found that major bruising of the oil palm fruitlets gave a higher amount of FFA content at all ripeness levels [6].

Chong et al 1993 used a hammering technique to crush the fruit spikelets and determined the FFA release. This technique causes higher FFA content which was $14 \%$ within one hour [7]. Nevertheless, the fruitlets were easily detached from the spikelets compared to fruitlets from the fruit bunches after being subjected to steam sterilization. This is due to the rapid steam contact with more surface areas between fruit spikelets than the enclosed fruits in a bunch [8]. However, this research did not determine the mechanical properties of the fruit spikelets.

Mechanical properties of the oil palm fruits, including mesocarp, nut and kernel are very important to know its characteristics in order to increase oil recovery and minimize energy usage in mills [9]. The mechanical properties such as compressive force $(\mathrm{N})$, deformation $(\mathrm{mm})$, energy $(\mathrm{J})$, and hardness $(\mathrm{N} / \mathrm{mm})$ on oil palm kernel were studied by Kabutey et al., 2013 [9]. Owolarafe at al., 2007 also studied the mechanical properties on two varieties of oil palm fruit (Dura and Tenera) [10]. However, currently, there is lack of research on the mechanical properties required to chop or cut the oil palm fruit spikelets.

Thus, this research was conducted to study the effect of chopping oil palm fruit spikelets on the rate of FFA released after it was chopped into different damage categories. The data are very useful to know the ample time required in delaying the enzymatic reaction that occurs after the chopping process to ensure production of good quality palm oil. The mechanical properties such as rupture force, deformation at rupture, hardness and energy at the break required when chopping the fruit spikelets were also investigated. It can be used to design and develop any milling equipment.

\section{MATERIALS AND METHODS}

\subsection{Determination of physical properties}

The ripe Tenera species of fresh fruit bunches (FFB) of palm oil were obtained from Taman Pertanian Universiti, Universiti Putra Malaysia. The FFB was chopped into fruit spikelets and 60 samples were randomly taken to measure the length, width and thickness. The measurement was taken by using a Vernier calliper (Mitutoyo, Japan) with an accuracy of $\pm 0.01 \mathrm{~mm}$ as shown in Fig-1.

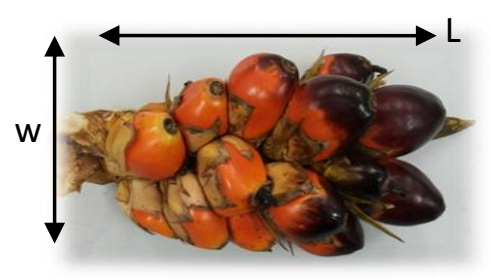

Fig-1: The measurement of the length (L) and width (w) of spikelet palm oil

\subsubsection{Measurement of mass}

The mass of the fruit spikelets was obtained by using a snap weight multiteda (Meltler, Toledo) with an accuracy \pm 0 . $01 \mathrm{~kg}$. The measurement was replicated for three times.

\subsection{Manually chopping of fruit spikelets using a knife blade}

For the first method, the fruit spikelets were chopped into categories of fruits with minor and major damage using a knife blade as shown in Table - 1. The minor damage category was defined as the damages that occurred on the mesocarp's surface while the major damage category was defined as the damages that occurred to the whole fruit including the nut and kernel. The chopped fruit spikelets were stored at room temperature for several storage periods which were $0 \mathrm{hr}, 0.5 \mathrm{hr}, 1 \mathrm{hr}, 1.5 \mathrm{hr}$ and $2 \mathrm{hr}$. After each of the storage periods, the chopped fruit spikelets were dried in the oven (Memmert, USA) for $24 \mathrm{hrs}$ at $103^{\circ} \mathrm{C}$ to extract the palm oil. The extraction method was carried out according to MPOB Test Methods 2004 [5].

Table - 1: The classification of minor and major damaged of fruit spikelets

\begin{tabular}{|c|c|}
\hline $\begin{array}{c}\text { Minor Damage } \\
\text { Definition: The area of } \\
\text { only. }\end{array}$ & $\begin{array}{c}\text { Definition: The fruits were } \\
\text { chopped into half. The } \\
\text { mesocarp and the kernel } \\
\text { areas were cut and exposed. }\end{array}$ \\
\hline
\end{tabular}




\subsection{Design of chopper blade}

The chopper blade was designed in x-type blade section to chop the fruit spikelets as shown in Fig-2. The dimension of the blade is $38.2 \mathrm{~cm}$ width (w) and $25.3 \mathrm{~cm}$ height (h). It is made of mild steel and the weight is $7.3 \mathrm{~kg}$. The chopper blade was fixed on the Instron Machine (Model 5566, USA) to chop the fruit spikelets. The mechanical properties of the chopped fruit spikelets were interpreted using the Bluehill2 software.

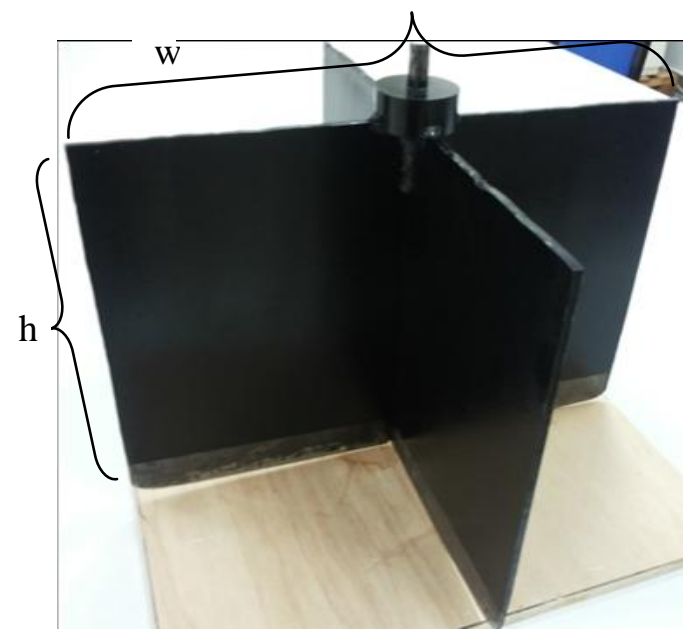

Fig-2: The fabricated chopper blade

\subsection{Chopping of fruit spikelets by Chopper Blade}

Fig 3 (a) shows the fruit spikelet being placed horizontally on the Instron machine. It was chopped at a constant velocity of $50 \mathrm{~mm} / \mathrm{min}$. After chopping, the chopped fruit spikelets were kept at different storage periods ranging from 0hr, 0.5hr, 1hr, 1.5hr and $2 \mathrm{hr}$ as shown in Fig - 3 (b).

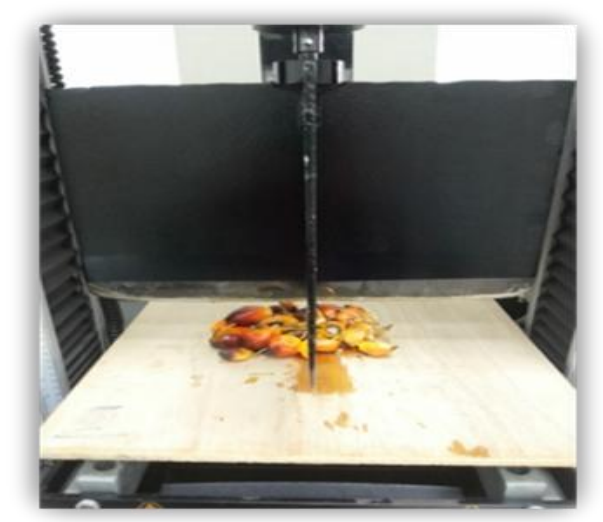

(a)

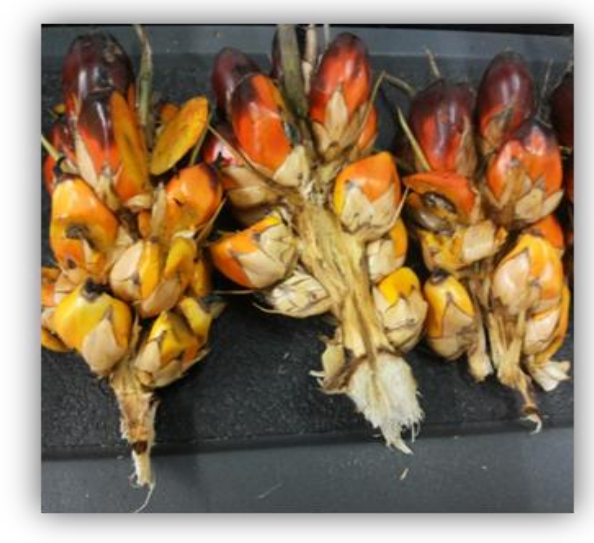

(b)

Fig - 3: (a) chopping of fruit spikelets using the fabricated chopper blade (b) The chopped fruit spikelets

\subsection{Determination of mechanical properties of chopped fruit spikelets}

The mechanical properties of chopped fruit spikelets were determined in this study. The rupture force, deformation at rupture, hardness and energy at the break were interpreted using the Bluehill2 software. The rupture force $(\mathrm{N})$ is defined as the compression load pressing force directed toward the fruit spikelets. Deformation (mm) or compressive extension is the loading direction taken by the blade to cut the fruits and it correlates to the rupture force of the fruits. The energy at break can be obtained from the area under the graph as shown in Fig - 4 [9]. The hardness $(\mathrm{N} / \mathrm{mm})$ was determined by the ratio of rupture force and deformation at rupture force [10].

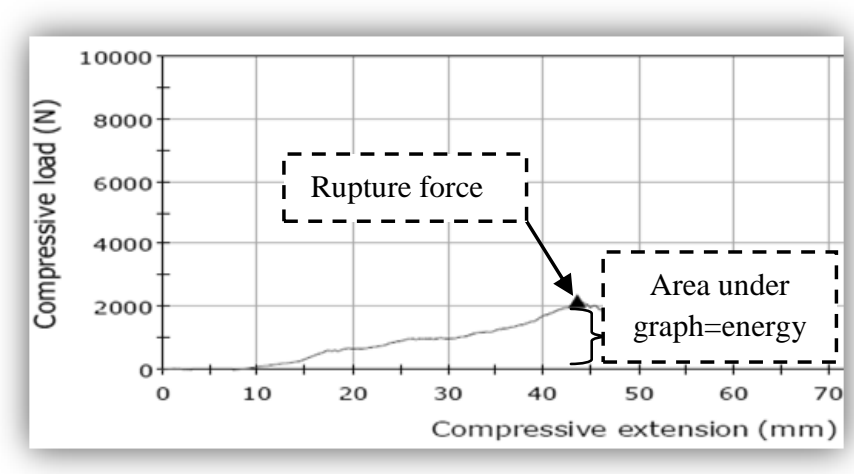

Fig - 4: The rupture force against deformation at rupture curve of fruit spikelets

\subsection{Extraction of the palm oil using Soxhlet extraction method}

The soxhlet extraction was carried out according to the MPOB Test Method p2. 5:2004[5]. 20g of mesocarp was weighed and placed into Whatman no 1 filter paper. The extraction was done using $300 \mathrm{ml}$ of hexane as a solvent at the temperature of $60^{\circ} \mathrm{C}$ and it was left about 4hours or until the orange colour had disappeared. The hexane solution was 
then removed using a rotary evaporator (Heidolph, USA) and left in the oven at $103^{\circ} \mathrm{C}$ for $2 \mathrm{hr}$ to remove any moisture. The oil yield was calculated to obtain the percentage of oil content using this equation:

$\%$ Oil content $=\left[\mathrm{m}_{1} / \mathrm{m}_{2}\right] \times 100 \%$

Where $\mathrm{m}_{2}=$ mass of oil extracted $($ gram $), \mathrm{m}_{1}=$ mass of sample (gram)

\subsection{Determination of free fatty acid content}

The free fatty acid content was determined by using the titration method as written in the MPOB Test Method with some modification [5]. $2 \mathrm{~g}$ of preheated oil (about $50{ }^{\circ} \mathrm{C}$ ) was weighed in a clean beaker. It was mixed with $50 \mathrm{ml}$ Iso propyl alcohol. The solution was neutralized by titration of $0.100 \mathrm{~N}$ sodium hydroxide. The percentage of FFA content was determined by this equation:

$\% \mathrm{FFA}=[25.6 \times \mathrm{V} \times \mathrm{N}] / \mathrm{W}$

Where: $\mathrm{V}=$ volume of sodium hydroxide used, $\mathrm{N}=0.1005$ $\mathrm{N}$ Normality (concentration) of sodium hydroxide used, $\mathrm{w}=$ Weight of oil used.

\section{RESULTS AND DISCUSSION}

\subsection{Mechanical properties of fruit spikelets}

\subsubsection{Length, width and mass}

The dimension of the fruit spikelets was obtained by measuring the length, width and mass. The data were analyzed by using Statistical program for social science (SPSS 20 software). Table - 2 shows the range of the length, width and mass of the fruit spikelets. The mean length, width and mass were $114.14 \mathrm{~mm}, 60.17 \mathrm{~mm}$ and $0.22 \mathrm{~kg}$ respectively. The standard deviation for the length, width and mass were found to be \pm 5 . $05, \pm 3.62$ and \pm 0.027 respectively. It was high because of the varying sizes, ages and pattern of fruit spikelets. Owolarafe et al 2007 also found the high variability of the fruitlet dimension because of the different size and species oil palm bunches [10].

Table - 2: The length, width and mass of the fruit spikelets

\begin{tabular}{|c|c|c|c|}
\hline \multirow{2}{*}{ Properties } & \multicolumn{3}{|c|}{ Range } \\
\cline { 2 - 4 } & Min & Max & $\begin{array}{c}\text { Mean } \\
\pm \text { Std. Deviation }\end{array}$ \\
\hline Length & 99.26 & 122.48 & $\begin{array}{c}114.14 \\
\pm 5.05\end{array}$ \\
(mm) & & & 60.17 \\
\hline Width & 51.43 & 70.57 & \pm 3.62 \\
(mm) & & & 0.22 \\
Mass (kg) & 0.17 & 0.290 & \pm 0.03 \\
\hline
\end{tabular}

\subsubsection{Rupture force, deformation at rupture, hardness and energy at the break chopping the fruit spikelets}

The rupture force, deformation at rupture, hardness and energy at the break required to chop the fruit spikelets were presented in the Table - 3. The data showed that the mean rupture force obtained was $2781 \mathrm{~N}$. The result obtained was high because the fruit spikelets consist of many fruitlets attached to the spikelets. Compared to the previous research, the mean rupture force to crack a Tenera fruitlet was $1149 \mathrm{~N}$ Owolarafe et al 2007 but they did not determine the deformation at rupture and the hardness of the fruitlet [10]. Deformation at rupture $(\mathrm{mm})$ refers to the compression extension of the chopper blade throughout the fruit spikelets. The mean of deformation at rupture was $45.53 \mathrm{~mm}$ and it is mostly depending on the size and thickness of the fruits. Apart from that, the mean of hardness was $61.02 \mathrm{~N} / \mathrm{mm}$. The hardness value of the fruit spikelets was high during chopping due to the presence of the kernel and nut. Similar results were explained by Kabutey et al 2013 on the hardness of oil palm kernel compared to fruits and nut [9], and also Karaj et al 2010 on the hardness of kernel Jatropha seeds [11]. Moreover, the fresh fruit spikelets consist of hard and woody stalk due to its lignocellulosic composite content such as cellulose, hemicellulose and lignin content [12]. The composite content also contributed to the higher mechanical properties needed to chop the fruit spikelets.

Table - 3: Rupture force, deformation at rupture, hardness and energy at the break to chop the fruit spikelets

\begin{tabular}{|c|c|c|c|}
\hline \multirow{2}{*}{ Properties } & \multicolumn{3}{|c|}{ Range } \\
\cline { 2 - 4 } & Min & Max & $\begin{array}{c}\text { Mean } \\
\pm \text { Std. Deviation }\end{array}$ \\
\hline Rupture force & 2001 & 3661 & 2781 \\
$(\mathrm{~N})$ & & & \pm 0.44 \\
\hline $\begin{array}{c}\text { Deformation at } \\
\text { rupture (mm) }\end{array}$ & 33.0 & 55.0 & 45.53 \\
\hline Hardness & 44.82 & 78.67 & \pm 5.19 \\
$(\mathrm{~N} / \mathrm{mm})$ & & & \pm 9.02 \\
\hline $\begin{array}{c}\text { Energy at break } \\
(\mathrm{J})\end{array}$ & 25.37 & 62.35 & 36.71 \\
& & & \pm 7.08 \\
\hline
\end{tabular}

\subsection{Effect of chopping of fruit spikelets on the free fatty acid content release rate}

Fig - 6 shows three categories of chopped fruit spikelets which represent minor damage, major damage and chopped fruit spikelets using the chopper blade. The rate of FFA content released from fruit spikelets with minor damage gradually increased from $0.94 \%$ up to $1.92 \%$ during the $2 \mathrm{hr}$ storage period. The chopped fruit spikelets using the chopper blade gave a slightly higher FFA content released compared to the fruit spikelets with minor damage. The highest rate of FFA content released was obtained by the fruit spikelets in the major damage category with values 
ranging from $1.6 \%$ to $5.69 \%$. There was a rapid increment in the FFA of the fruit spikelets that were major damage compared to the fruit spikelets with minor damage and chopped fruit spikelets using the chopper blade. This is due to the larger damaged area exposed to microorganisms. Hence, it accelerated the lipase enzymatic activity and produced higher rates of FFA content released within $2 \mathrm{hr}$ storage period.

For all the categories, the FFA contents increased significantly with the storage period whereby the correlation analyses showed a strong positive correlation for minor damaged $(r=0.958)$, major damaged $(r=0.980)$ and chopped fruit spikelets using the chopper blade $(r=0.902)$. In addition, the relationship between the storage periods of all chopped fruit spikelets and FFA content showed significant differences at $\mathrm{p}<0.05$. The result was supported by a previous research done by Hadi et al., 2009. It was found that the development of the FFA content of oil palm fruit was proportionally increased with the area of bruises for all ripeness levels [6]. Tagoe et al 2012 also indicated that the FFA content was increased with the length of storage time [13].

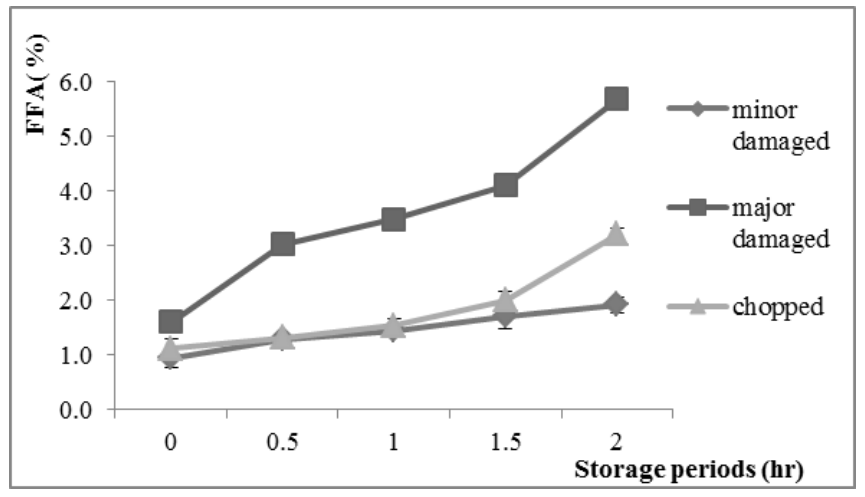

Fig - 6: The FFA content against storage periods of minor and major damaged fruit spikelets (knife blade) and chopped fruit spikelets (chopper blade)

\section{CONCLUSIONS}

In this study, the mechanical properties to chop the fruit spikelets were obtained and can be used to design a chopper blade machine or any related equipment in the mills.

It was found that the rate of FFA content released was significantly influenced by the level of fruit damage after chopping and it increased proportionally with the length of storage periods. The FFA content from the fruit spikelets with major damage can reach above $5 \%$ if there was no pretreatment process done immediately. Therefore, it is of utmost importance that the chopped fruits to be subjected to immediate sterilization in order to deactivate the lipase activity.

\section{REFERENCES}

[1]. Ojomo, A.O., Ologunagba, F.O., and Alagha, S.A.(2010). Performance Evaluation of a Palm Fruit Bunch Stripper. Journal of Engineering and Applied Sciences.

[2]. Tan, C.H., Hasanah, M.Ghazali., Ainie, K., Chin-Ping, $\mathrm{T}$ and Abdul, A.Ariffin. (2009). Extraction and Physicochemical Properties of Low Free Fatty Acid Crude Palm Oil. Food Chemistry 113 (2009) 645-650.

[3]. Sivasothy, K., Mohd Halim, R., and Basiron, Y. (2005). A New System For Continuous Sterilization of Oil Palm Fresh Fruit Bunches. Journal of Oil Palm Research Vol. 17 December 2005, P. 145- 151.

[4]. Sivasothy, K., and Mohd Halim, R. (2006). A New System For Continuous Sterilization of Oil Palm Fresh Fruit Bunches. Journal of Oil Palm Research Vol. 17 December 2005 P.145-151.

[5]. Malaysian Palm Oil Board (MPOB) (2004). MPOB Test Methods.

[6]. Hadi, S., Ahmad, D., and Akande, F.K. (2009). Determination of the Bruise Indexes of Oil Palm Fruits. Journal of Food Engineering 95 (2009) 322-326.

[7]. Chong, C.L., and Sambanthamurthi, R. (1993). Effects Of Mesocarp Bruising on the Rate of Free Fatty Acid Release in Oil Palm Fruits. International Biodeterioration \& Biodegradation 31 (1993) 65-70.

[8]. Babatunde, O.O., Ige, M.T., and Makanjuola, G.A., (1988). Effect of Sterilization on Fruit Recovery in Oil Palm Fruit Processing. Journal of Agricultural Engineering Research - J Agr Eng Res 01/1988; 41(2):75-79.

[9]. Kabutery,A., Divisova, M., Sedlack,L., W.E. Boatri,W.E., Svatonova, T., and Sigalingging, R. (2013). Mechanical Behaviour of Oil Palm Kernels (Elaeis Guineensis). Scientia Agriculturae Bohemica, 44, 2013 (1): $18-22$

[10]. Owolarafe, O.K., Olabige, M.T, and Faborode, M.O. (2007). Physical and Mechanical Properties of Two Varieties of Fresh Oil Palm Fruit. Journal of Food Engineering 78 (2007) 1228-1232.

[11]. Karaj, S., and Miller, J. (2010). Determination Of Physical, Mechanical And Chemical Properties Of Seeds And Kernels Of Jatropha Curcas L. Industrial Crops And Products.

[12]. Nazir, S., Wahjoedi, B.A., Yussof, A.W., and Abdullah, M.A. (2013). Eco-Friendly Extraction and Characterization of Cellulose From Oil Palm Empty Fruit Bunches. 'MCC From OPEFB,' Bioresource 8 (2), 21612172. 
[13]. Tagoe, S.M.A., Dickinson, M.J. and Apetorgbor, M.M. (2012). Factors Influencing Quality of Palm Oil Produced At Cottage Industry Level In Ghana. International Food Research Journal 19(1): 271-278 (2012).

\section{BIOGRAPHIES}

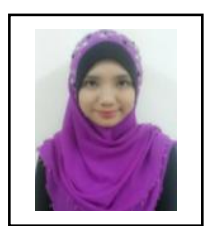

Fatin Syakirah Bt Ali

(Postgraduate Student)

Faculty of Engineering, Universiti

Putra Malaysia.

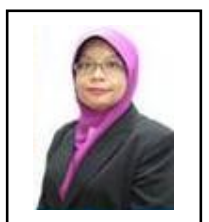

Assoc. Prof. Dr. Rosnah Bt

Shamsuddin

(Lecturer)

Faculty of Engineering, Universiti

Putra Malaysia.

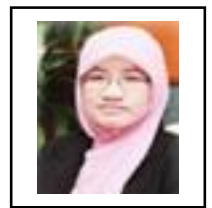

Prof. Dr. Robiah Bt Yunus

(Director)

Institute of Advanced Technology,

Universiti Putra Malaysia. 